\title{
Microwave-Assisted Synthesis of SiC Nanoparticles for the Efficient Adsorptive Removal of Nitroimidazole Antibiotics from Aqueous Solution
}

\author{
Ali Fakhri ${ }^{1, *}$, Sahar Rashidi ${ }^{2}$, Mohammad Asif ${ }^{3, *}$ and Ahmed A. Ibrahim ${ }^{3}$ \\ 1 Young Researchers and Elites Club, Science and Research Branch, Islamic Azad University, Tehran, Iran \\ 2 Department of Chemical Engineering, South Tehran Branch, Islamic Azad University, Tehran, Iran; \\ srashidi05@gmail.com \\ 3 Department of Chemical Engineering, King Saud University, Riyadh 11421, Saudi Arabia; aidid@ksu.edu.sa \\ * Correspondence: ali.fakhri88@yahoo.com (A.F.); masif@ksu.edu.sa (M.A.); \\ Tel.: +98-21-2287-3079 (A.F.); +966-56-981-7045 (M.A.)
}

Academic Editor: Manuel Ocaña Jurado

Received: 8 December 2016; Accepted: 13 February 2017; Published: 20 February 2017

\begin{abstract}
Environmental pollution caused by the improper disposal of pharmaceuticals is a matter of global concern, and warrants immediate attention. Of particular concern is the aquatic contamination caused by the increasing use of antibiotics, which could give rise to superbugs. While researchers have mainly focused on improving the adsorption capacity of mostly activated carbon-based adsorbents, we have developed a non-conventional adsorbent ( $\mathrm{SiC}$ nanoparticles) in the present work for the adsorptive removal of four different nitroimidazole antibiotics, namely metronidazole (MNZ), dimetridazole (DMZ), ronidazole (RNZ), and tinidazole (TNZ). In addition to the unique properties which are inherent to $\mathrm{SiC}$, the present adsorbent not only possesses a high adsorption capacity, but also shows one of the highest adsorption rates; both of which are prerequisites for an efficient and cost-effective adsorption-based separation technology. Silicon carbide ( $\mathrm{SiC}$ ) nanoparticles, synthesized by a microwave-assisted method, were thoroughly characterized using X-ray diffraction, scanning electron microscopy, transmission electron microscopy, and the Brunauer-Emmett-Teller method. The adsorption isotherm data were accurately described by the Langmuir isotherm model. On the other hand, the adsorption kinetics, closely represented by the pseudo-second order kinetic model, were faster than most previously reported adsorbents. The reaction rate constants were 0.0089 , $0.0079,0.0072$, and $0.0055 \mathrm{~g} /$ (mg min), for MNZ, DMZ, RNZ, and TNZ, respectively.
\end{abstract}

Keywords: microwave-assisted method; SiC nanoparticles; efficient adsorptive removal; nitroimidazole antibiotics

\section{Introduction}

Antibiotics have increasingly been applied in the treatment and prevention of a wide variety of bacterial infections. However, their occurrence in the aquatic environment is an emerging environmental problem, which is mostly caused by the effluents of pharmaceutical industries and hospitals, in addition to veterinary and human medication uses [1,2]. Approximately $30 \%-90 \%$ of antibiotics administered remain un-degraded in the human or animal body, and are largely excreted as an active compound [3,4]. This is a matter of grave concern, as the prevalence of antibiotics in the natural environment can give rise to superbugs, which are drug-resistant bacteria. The removal of such pollutants are therefore of paramount importance. 
In the present study, we focus our attention on the widely used nitroimidazoles antibiotics, which possess antibacterial and anti-inflammatory properties, and are therefore commonly prescribed for treating infections caused by protozoans and anaerobic bacteria, such as Giardia lamblia and Trichomonas vaginalis [5,6]. Metronidazole (MNZ) is a nitroimidazole antibiotic, which is commonly used for the treatment of anaerobic bacteria and protozoa [7]. Dimetridazole (DMZ) is a drug that combats protozoan infections. Ronidazole (RNZ) is an antiprotozoal agent employed in veterinary medicine to treat histomoniasis and swine dysentery [8]. Tinidazole (TNZ) is an anti-parasitic drug used against protozoan infections [9]. The chemical and physical characteristics of MNZ, DNZ, RNZ, and TNZ, are summarized in Table 1.

Table 1. Physicochemical properties of nitroimidazole antibiotics, DMZ: Dimetridazole; MNZ: Metronidazole; RNZ: Ronidazole; TNZ: Tinidazole.

\begin{tabular}{ccccc}
\hline Nitroimidazole & $\begin{array}{c}\text { Molecular } \\
\text { Formula }\end{array}$ & $\begin{array}{c}\text { Molecular Weight } \\
\left(\mathbf{g} \cdot \mathbf{m o l} \mathbf{m o l}^{-\mathbf{1}}\right)\end{array}$ & pKa & $\begin{array}{c}\text { Melting Point } \\
\left({ }^{\circ} \mathbf{C}\right)\end{array}$ \\
\hline $\mathrm{DMZ}$ & $\mathrm{C}_{5} \mathrm{H}_{7} \mathrm{~N}_{3} \mathrm{O}_{2}$ & 141.13 & 2.81 & $138-141$ \\
$\mathrm{MNZ}$ & $\mathrm{C}_{6} \mathrm{H}_{9} \mathrm{~N}_{3} \mathrm{O}_{3}$ & 171.15 & 2.58 & $159-163$ \\
$\mathrm{RNZ}$ & $\mathrm{C}_{6} \mathrm{H}_{8} \mathrm{~N}_{4} \mathrm{O}_{4}$ & 200.15 & 1.32 & $168-169$ \\
$\mathrm{TNZ}$ & $\mathrm{C}_{8} \mathrm{H}_{13} \mathrm{~N}_{3} \mathrm{O}_{4} \mathrm{~S}$ & 247.27 & 2.30 & $118-120$ \\
\hline
\end{tabular}

Several separation technologies, e.g., adsorption, photo-degradation, ozonation, and biological methods etc., have been suggested for the removal of nitroimidazoles from aqueous solutions [10-22]. However, the choice of the most suitable technology depends upon its cost-effectiveness for large-scale applications. Adsorptive removal using adsorbents with large surface areas is mostly preferred when low concentrations of organic and inorganic contaminants are involved. For the removal of nitroimidazoles, the activated carbon-based adsorbents have mostly been investigated. For example, Ahmed and Theydan $[10,11]$ prepared different kinds of activated carbon samples using Siris seed pods, for the adsorption of metronidazole. Activated carbon produced by microwave-induced $\mathrm{KOH}$ activation yielded the best results, with an adsorption capacity of $196.31 \mathrm{mg} / \mathrm{g}$. The removal of metronidazole was governed by the second-order adsorption kinetics. The rate constant at $303 \mathrm{~K}$ was found to be $0.0039,0.0013$, and $0.0011 \mathrm{~g} /(\mathrm{mg} \mathrm{min}$ ), for 20,60 , and $100 \mathrm{mg} / \mathrm{g}$ of initial metronidazole concentration, respectively. It took as long as $180 \mathrm{~min}$ for the equilibrium to be established [10,11]. On the other hand, the use of activated carbon cloth by Orellana-Garcia et al. [12] yielded a higher uptake of the nitroimidazoles (500 mg/g for MNZ and $600 \mathrm{mg} / \mathrm{g}$ for DMZ). However, the adsorption rate was significantly slower, taking as long as $220 \mathrm{~min}$ to reach equilibrium. Recently, Flores-Cano et al. [13] produced activated carbon samples from coffee residues and almond shells possessing surface areas in the range of 104- $222 \mathrm{~m}^{2} / \mathrm{g}$. Though the coffee residue-based activated carbon was better than that produced from the almond shell, its uptake was limited to 126 and $111 \mathrm{mg} / \mathrm{g}$ for MNZ and DMZ, respectively. Nevertheless, the authors argued that the performance of their adsorbents was superior to other high surface area adsorbents, if the antibiotic removal was evaluated on the basis of the surface area, instead of the commonly used mass basis. However, these adsorbents showed higher rates of antibiotic removal when compared to most other activated carbon-based adsorbents, since the equilibrium was established in only $50 \mathrm{~min}$. Using Fe-modified sepiolite, Ding and Bian [14] were able to significantly enhance the uptake of the metronidazole, as compared to the original low-cost sepiolite. Yet, the adsorption capacity of the modified sepiolite (Langmuir isotherm maximum uptake, $Q_{m}=5.62 \mathrm{mg} / \mathrm{g}$ at $T=303 \mathrm{~K}$ and $R^{2}=0.9470$ ) was substantially lower than most other adsorbents reported in the literature. Despite its poor adsorption capacity, the adsorption kinetics were relatively faster (equilibrium time $<30 \mathrm{~min}$ ), when compared to other adsorbents reported in the literature. Adsorption is a surface-based rate process that causes an increase in the adsorbate concentration at the adsorbent surface, owing to the surface forces arising from the adsorbent-adsorbate interaction. In the present, nitroimidazole-adsorbent interaction is mainly attributed to the cation exchange and surface 
complexation reactions (H-bonding and other polar interactions) between multifunctional antibiotic molecules [23].

Clearly, most researchers have focused on improving the uptake capacity of adsorbents for the removal of contaminants. For the development of an efficient and cost-effective adsorptive separation technology, however, both the adsorption capacity and the adsorption rate are equally important. In fact, adsorbents with higher adsorption and desorption rates are a prerequisite for the economy of any large-scale water-treatment process, where multiple cycles based on the adsorbent regeneration are employed. In the present work, we therefore report the preparation and characterization of a novel adsorbent that possesses both a high removal capacity, and a high uptake rate, for nitroimidazoles. To this end, we consider silicon carbide ( $\mathrm{SiC})$, which is a non-oxide ceramic with a high melting point, high hardness, high wear resistance, low thermal expansion coefficient, and good chemical resistance [23-25]. These properties make $\mathrm{SiC}$ useful for numerous applications, such as polishing paste, grinding, wear-resistant, and high-temperature structural materials, catalyst supports, filters for molten metal or hot gases, and reinforcement in the preparation of composites [23,26-29]. These properties of $\mathrm{SiC}$ are equally important for its application as a granular medium for the adsorptive removal of antibiotics, based on fixed/fluidized bed processing of the contaminated water with multiple regeneration cycles of the adsorbent. In the following, we first describe the synthesis of $\mathrm{SiC}$ nanoparticles via sol-gel and microwave radiation. Its rigorous characterization is then reported. The efficacy of the $\mathrm{SiC}$ nanoparticles, thus prepared, is investigated for the removal of four different antibiotics, i.e., DMZ, MNZ, RNZ, and TNZ, from aqueous solutions. The influence of solution $\mathrm{pH}$ and temperature are examined on the antibiotic uptake efficiency of the adsorbent. Both the experimental equilibrium and kinetic data were processed in conjunction with well-known theoretical models, in order to examine their capability to accurately describe the experimental data. Finally, the removal efficacy of the present adsorbent is compared with previously reported adsorbents in the literature.

\section{Materials and Methods}

\subsection{Preparation of SiC Nanoparticles}

Raw materials used in the present study were obtained from Sigma-Aldrich Ltd. (Sydney, Australia). Sol was prepared by mixing $20 \mathrm{~g}$ of glucose, $25 \mathrm{~mL}$ of water, and $15 \mathrm{~mL}$ of ethanol. A total of $35 \mathrm{~mL}$ of TEOS was the added to the mixture. During mixing, the $\mathrm{pH}$ was controlled by gradual addition of $0.05 \mathrm{M} \mathrm{HCl}$. Alcohol was removed from the sol by heating at $40{ }^{\circ} \mathrm{C}$. This led to the condensation of particles, which were joined together and formed polymeric gel containing siloxane bonds, with a carbonaceous phase in its structure. Since the application of microwave heating provides low cost, rapid preparation, and the highly uniform growth and aggregation of particles [24], the derived gel was heated under microwave irradiation with an output power of $500 \mathrm{~W}$ for $20 \mathrm{~min}$. The gel was obtained after drying at $110^{\circ} \mathrm{C}$ for $12 \mathrm{~h}$. After sonication in an ultrasonic homogenizer (APU500, $40 \mathrm{kHz}, 100 \mathrm{~W}$, Adeeco Co., Tehran, Iran), the xerogel was placed in an alumina tube furnace, and heated to $1400-1500{ }^{\circ} \mathrm{C}$ under a flowing argon atmosphere $(3 \mathrm{~h})$. Finally, the products were washed with distilled water and absolute ethanol several times, and dried at $80^{\circ} \mathrm{C}$ for $12 \mathrm{~h}$.

\subsection{Characterization}

Scanning electron microscopy (SEM; JSM-5600, JEOL, Tokyo, Japan) and transmission electron microscopy (TEM; JEM-2100F HR, 200 kV, JEOL, Peabody, MA, USA) were used to characterize the morphology of the $\mathrm{SiC}$ particle. Nitrogen adsorption-desorption isotherm measurements $(77.4 \mathrm{~K}$ using ASAP2010, Micromeritics, Norcross, GA, USA) and X-ray diffraction (XRD; Philips X'Pert, PANalytical, Warszawa, Poland) were also performed to characterize the structure of the $\mathrm{SiC}$ particle. 


\subsection{Equilibrium Studies}

A fixed amount of adsorbent $(0.1 \mathrm{~g})$ was added to $250 \mathrm{~mL}$ Erlenmeyer flasks containing $100 \mathrm{~mL}$ of different initial concentrations (30,60, and $90 \mathrm{mg} / \mathrm{L}$ ) of nitroimidazole solutions, without adjusting the $\mathrm{pH}$. Experiments were carried out at initial $\mathrm{pH}$ values that ranged from 2 to 10 . The initial $\mathrm{pH}$ of the solution was adjusted to the desired value by adding either $\mathrm{HCl}$ or $\mathrm{NaOH}$ solution. The effect of the presence of electrolytes on the adsorption was analyzed by increasing the concentrations of $\mathrm{KCl}$ (0.005-0.1 M). At equilibrium, the concentration of nitroimidazole was measured at $308 \mathrm{~nm}$ (RNZ), $317 \mathrm{~nm}$ (TNZ), and $320 \mathrm{~nm}$ (MNZ and DMZ), by a double beam UV-vis spectrophotometer (Model UV 1601; Shimadzu, Kyoto, Japan). Each experiment was conducted in duplicate, under identical conditions. For computing the amount of antibiotics adsorbed at equilibrium, $q_{e}(\mathrm{mg} / \mathrm{g})$, the following material balance was used:

$$
q_{e}=\left(C_{0}-C_{e}\right)\left(\frac{V}{W}\right)
$$

where $C_{0}$ and $C_{e}$ are the initial and final equilibrium concentrations of nitroimidazole in $\mathrm{mg} / \mathrm{L}$, respectively. Also, $\mathrm{W}$ is the adsorbent mass (g), while $V$ is the volume of the aqueous solution (L).

\subsection{Kinetic and Equilibrium Models}

The experimental data for the adsorption kinetics of nitroimidazole antibiotics onto SiC NPs were analyzed using different models, which are listed in the following.

(i) The pseudo-first order kinetic model is given as follows [30]:

$$
\log \left(q_{e}-q_{t}\right)=\frac{k_{1}}{2.303} t+\log \left(q_{e}\right)
$$

where $q_{t}$ is the amount of nitroimidazoles adsorbed $(\mathrm{mg})$ per unit mass $(\mathrm{g})$ of the adsorbent at time $t$, and $k_{1}$ is the rate constant in $\left(\mathrm{min}^{-1}\right)$ of the pseudo-first order kinetics.

(ii) The pseudo-second order kinetic model is given as follows [31]:

$$
\frac{t}{q_{t}}=\frac{t}{q_{e}}+\frac{1}{k_{2} q_{e}^{2}}
$$

where $k_{2}$ is the rate constant in $(\mathrm{g} /(\mathrm{mg} \mathrm{min}))$ of the pseudo-second order kinetics.

(iii) The intra-particle diffusion kinetic model is given as follows [32]:

$$
q_{t}=K_{i} t^{1 / 2}+C,
$$

where $C$ is the intercept and $K_{i}$ is the intra-particle diffusion rate constant $\left(\mathrm{mg} /\left(\mathrm{g} \cdot \mathrm{min}^{1 / 2}\right)\right)$.

The equilibrium experimental data were analyzed using Langmuir, Freundlich, and Flory-Huggins isotherm models. These isotherms are listed in the following.

(i) The Langmuir isotherm model is given as follows [33]:

$$
\left(\frac{C_{e}}{q_{e}}\right)=\frac{1}{Q_{m}} C_{e}+\frac{1}{K_{L} Q_{m}}
$$

where $Q_{m}$ is the maximum adsorption capacity $(\mathrm{mg} / \mathrm{g}$ ) that corresponds to monolayer coverage, and $K_{L}$ is the Langmuir isotherm constant $(\mathrm{L} / \mathrm{mg})$.

(ii) The Freundlich isotherm model is given as follows [34]:

$$
\ln \left(q_{e}\right)=\ln \left(K_{F}\right)+\frac{1}{n} \ln \left(C_{e}\right),
$$


where $q_{e}(\mathrm{mg} / \mathrm{g})$ is the equilibrium nitroimidazole concentration on SiC NPs, while $K_{F}$ and $1 / n$ are constants of the isotherm model.

(iii) The Flory-Huggins model is given as follows [35]:

$$
\log \frac{\theta}{C_{e}}=\log K_{F H}+n_{F H} \log (1-\theta),
$$

where $\theta$ is the degree of surface coverage, $n_{F H}$ is the number of nitroimidazole molecules that occupy the adsorption sites, and $K_{F H}$ is the equilibrium constant of adsorption.

\section{Results and Discussion}

\subsection{Characterization of SiC Nanoparticles}

The XRD pattern presented in Figure 1 shows strong and sharp diffraction peaks, indicating the crystalline structure of the product. The diffraction peaks at approximately $35.81,41.41,60.21,71.91$, and 75.61, can be indexed as (111), (200), (220), (311), and (222) planes of $\beta$-SiC (Joint Committee on Powder Diffraction Standards (JCPDS) card No. 29-1129), respectively. The crystallite size of the nanoparticles was estimated using the Debye-Scherrer equation:

$$
D=\frac{k \lambda}{\beta \cos \theta}
$$

where $D$ is the diameter of nanoparticles, $k=0.94$ is the dimensionless shape factor, $\lambda$ (wavelength of $\mathrm{X}$-rays used) $=1.5406 \times 10^{-10}, \beta$ is the full width at half-maximum, and $\theta$ is the Bragg angle. Its value was found to be $25 \mathrm{~nm}$.

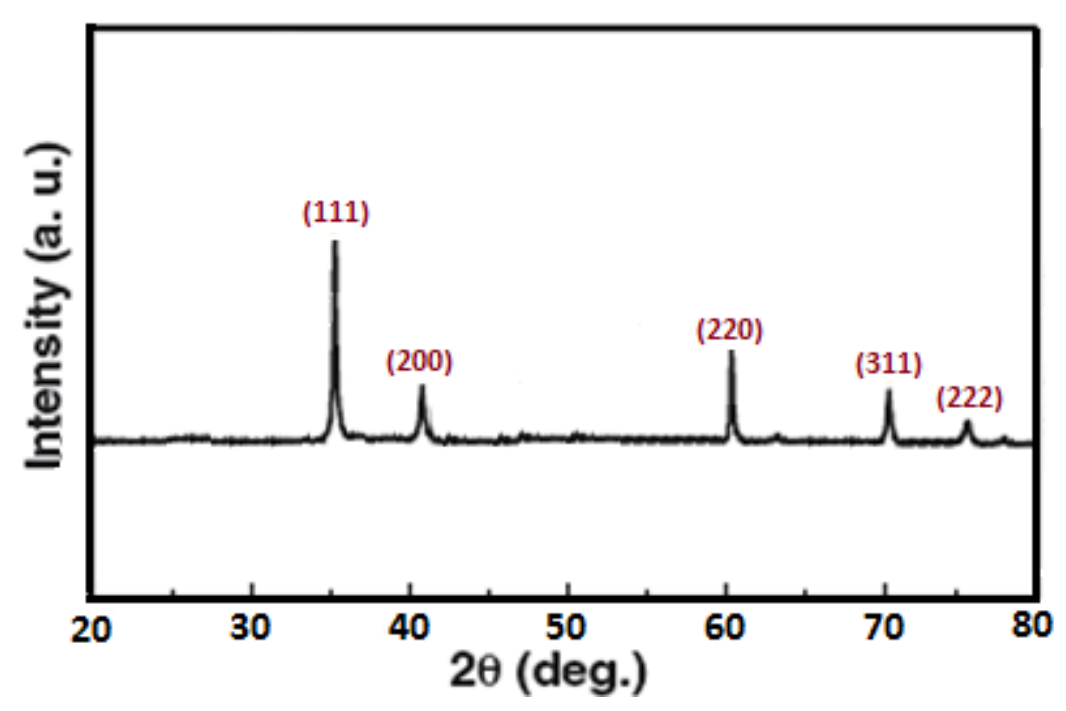

Figure 1. X-ray diffraction pattern of SiC nanoparticles.

The morphology and structure of the as-prepared SiC products were characterized by SEM and TEM in the present study. Figure 2A presents the TEM image of SiC nanoparticles. Numerous nanoparticles with semi-spherical morphology were observed from the TEM image. The particles are approximately $10-40 \mathrm{~nm}$ in size. Their diffraction patterns indicate three perfect diffraction rings, which correspond to the (311), (220) and (111) planes of cubic SiC. Figure 2B shows typical scanning electron micrographs of $\mathrm{SiC}$ nanoparticles. Single-phase primary particles with almost spherical-shaped nanocrystallites were observed. According to this figure, it can be observed that after the removal of the volatile materials, precursor particles form a nearly nanosized structure with a semi spherical morphology. 

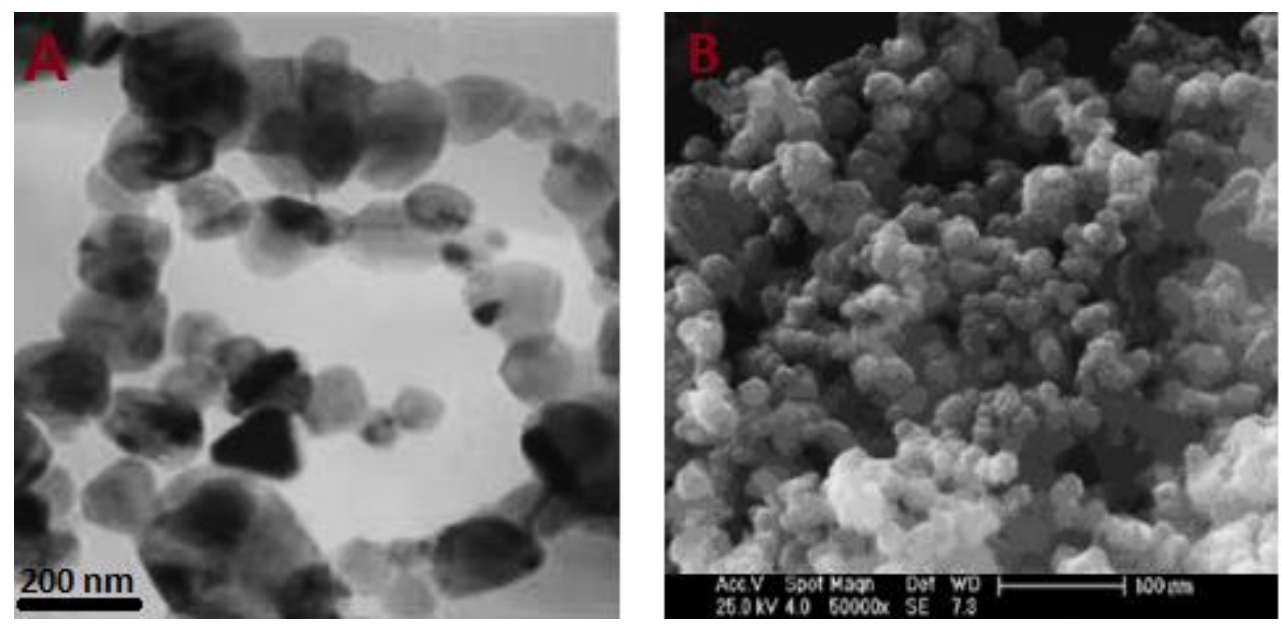

Figure 2. Transmission electron microscopy (TEM) (A) and scanning electron microscopy (SEM) images (B) of $\mathrm{SiC}$ nanoparticles.

The nitrogen adsorption and desorption isotherms for the $\mathrm{SiC}$ nanoparticles were also determined. The total pore volume and specific surface area were $0.06 \mathrm{~cm}^{3} \cdot \mathrm{g}^{-1}$ and $39.43 \mathrm{~m}^{2} \cdot \mathrm{g}^{-1}$, respectively.

\subsection{Adsorption Study}

Figure 3 shows the effect of contact time on the nitroimidazole adsorption onto SiC NPs, for the initial concentration, $C_{0}=30 \mathrm{mg} \cdot \mathrm{L}^{-1}$. Nitroimidazole adsorption rapidly increased with time and then reached equilibrium. The contact time required to reach equilibrium was almost $20 \mathrm{~min}$. The removal rate of the adsorbate is higher in the beginning because of the large surface area of the adsorbent available for adsorption, which gradually decreased with the progress of time.

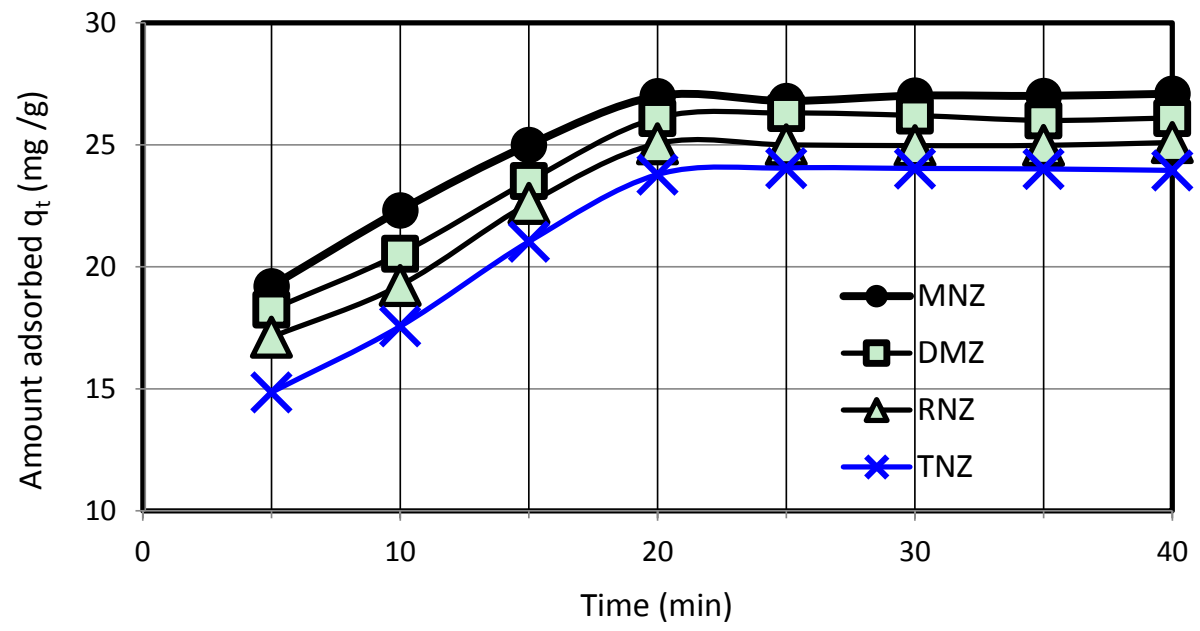

Figure 3. Effects of contact time on the adsorption of nitroimidazoles onto $\mathrm{SiC} \mathrm{NPs}\left(C_{0}=30 \mathrm{mg} / \mathrm{L}\right.$, $T=25^{\circ} \mathrm{C}$; adsorbent dose $=0.1 \mathrm{~g}, \mathrm{pH}=8$ ).

The $\mathrm{pH}$ of the solution strongly influences adsorbents' surface charge and the ionization of other species present in the aqueous solution. While hydrogen and hydroxyl ions are strongly adsorbed, the adsorption of other ions is often affected by the $\mathrm{pH}$ of the solution. Figure 4 shows the effect of $\mathrm{pH}$ on nitroimidazole removal by adsorption on $\mathrm{SiC} \mathrm{NPs}$ at an initial concentration of $30 \mathrm{mg} \cdot \mathrm{L}^{-1}$, in the $\mathrm{pH}$ range of 1 to 11 . The adsorption capacity of nitroimidazoles by SiC NPs increased with increasing 
$\mathrm{pH}$, and reached a maximum value at $\mathrm{pH} 8$. A slight decrease in nitroimidazole removal was often observed at a $\mathrm{pH}$ greater than 9.

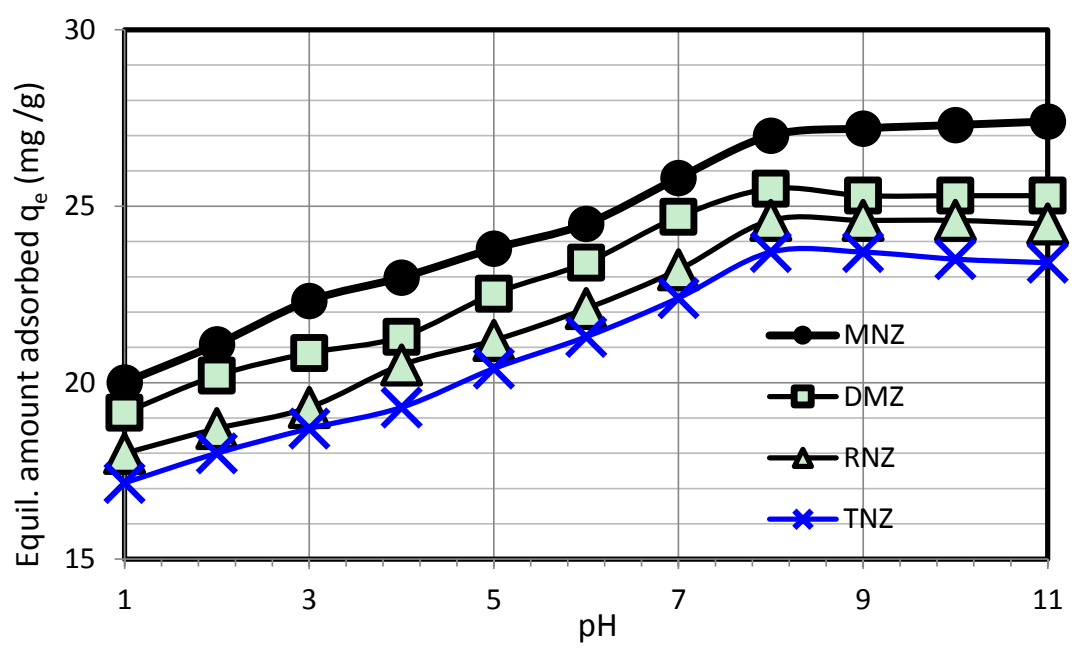

Figure 4. Effects of initial $\mathrm{pH}$ on the adsorption of nitroimidazoles onto $\mathrm{SiC}$ NPs $\left(C_{0}=30 \mathrm{mg} / \mathrm{L}\right.$, $T=25^{\circ} \mathrm{C}$, adsorbent dose $=0.1 \mathrm{~g}$ ).

Extensive investigations on nitroimidazole adsorption have revealed that its uptake strongly depends upon the concentration and nature of the electrolyte ionic species added to the ion bath [36,37]. The effect of inorganic salt $(\mathrm{KCl})$ on the adsorption rate of nitroimidazole on SiC NPs was investigated. However, the presence of inorganic salt did not influence the adsorption rate of nitroimidazole. These results confirm that the interactions involved in adsorption are not electrostatic.

\subsection{Investigation of Adsorption Isotherms and Kinetics}

Adsorption isotherm models describe the nature of interaction between the adsorbate and the adsorbent, and yield important information about the mechanisms of adsorption. In the present study, three different isotherm models, represented by Equations (5)-(7), were used to fit the experimental data. The isotherm parameters are reported in Table 2, along with $R^{2}$ values. It is clear that the Langmuir isotherm model best describes the experimental data for nitroimidazole adsorption on $\mathrm{SiC}$ NPs. Figure 5 further highlights the excellent agreement between the experimental data and the Langmuir isotherm model. This indicates a monolayer adsorption of the antibiotics on the vacant adsorption sites available on the surface of the SiC NPs, such that a dynamic equilibrium exists between the two. Moreover, it confirms that available vacant sites on the SiC NPs, though fixed in number, are of equal size with similar shapes, and can hold only one antibiotic molecule.

Table 2. Isotherm model parameters for nitroimidazole adsorption onto SiC NPs.

\begin{tabular}{cccccccccc}
\hline \multirow{2}{*}{ Isotherm Model } & \multicolumn{3}{c}{ Langmuir } & \multicolumn{3}{c}{ Freundlich } & \multicolumn{3}{c}{ Florry-Huggins } \\
\cline { 2 - 10 } & $\boldsymbol{Q}_{\boldsymbol{m}}$ & $\boldsymbol{K}_{\boldsymbol{L}}$ & $\boldsymbol{R}^{\mathbf{2}}$ & $\boldsymbol{n}$ & $\boldsymbol{K}_{\boldsymbol{F}}$ & $\boldsymbol{R}^{\mathbf{2}}$ & $\boldsymbol{K}_{\boldsymbol{F H}}$ & $\boldsymbol{n}_{\boldsymbol{F H}}$ & $\boldsymbol{R}^{\mathbf{2}}$ \\
\hline MNZ & 114.817 & 0.103 & 1.0000 & 1.971 & 16.481 & 0.9784 & 0.1125 & 2.065 & 0.9947 \\
DMZ & 119.786 & 0.071 & 0.9999 & 1.945 & 15.625 & 0.9866 & 0.0659 & 1.161 & 0.9980 \\
RNZ & 126.859 & 0.051 & 0.9999 & 1.722 & 10.655 & 0.9878 & 0.0513 & 1.165 & 0.9974 \\
TNZ & 126.755 & 0.042 & 1.0000 & 1.672 & 9.029 & 0.9879 & 0.0392 & 1.008 & 0.9979 \\
\hline
\end{tabular}




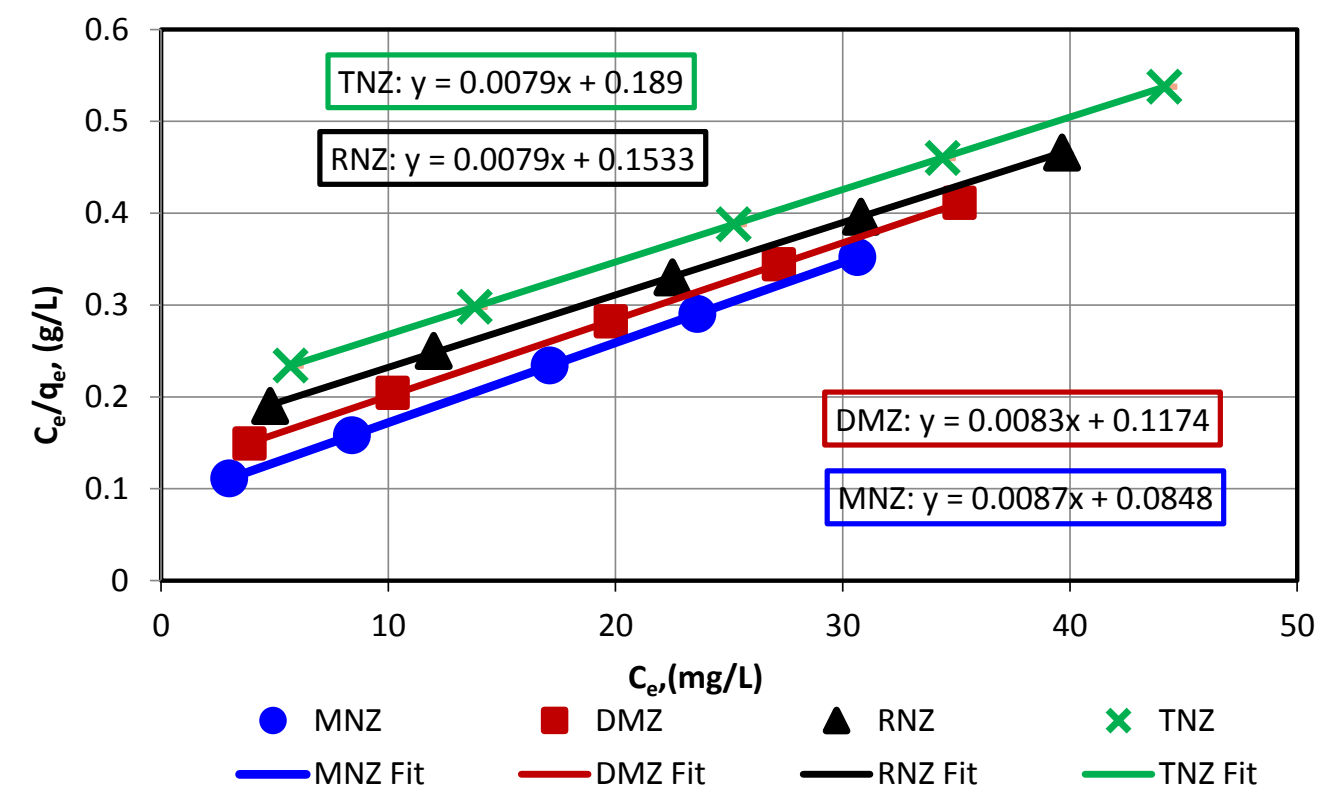

Figure 5. Langmuir model for nitroimidazole adsorption onto $\mathrm{SiC}$ NPs $\left(T=25{ }^{\circ} \mathrm{C}\right.$; adsorbent dose $=0.1 \mathrm{~g}, \mathrm{pH}=8)$.

A dimensionless constant separation factor $R_{L}$ is defined, to determine whether an adsorption is favorable or not. Adsorption is irreversible when $R_{L}$ is 0 ; favorable when $R_{L}$ is between 0 and 1 ; linear when $R_{L}$ is 1 ; and unfavorable when $R_{L}$ is greater than $1 . R_{L}$ is defined as follows:

$$
R_{L}=\frac{1}{1+K_{L} C_{0}}
$$

All of the computed values of $R_{L}$ were in the range of $0.5-0.6$ for SiC NPs, thereby confirming that the adsorption processes for all of the four different nitroimidazole antibiotics investigated here are favorable.

The adsorption kinetics describe the rate of the uptake of the nitroimidazoles on the silicon carbine nanoparticles synthesized here. The mechanism and the potential rate-controlling steps involved in the adsorption were examined using three kinetic models, namely, pseudo-first order (Equation (2)), pseudo-second order (Equation (3)), and intraparticle diffusion (Equation (4)). The parameters $k_{1}$ and $q_{e}$ for the pseudo-first order kinetic model were determined from the slope and intercept of the plots of $\ln \left(q_{e}-q_{t}\right)$ versus $t$, and are reported in Table 3, along with the values of the correlation coefficient $R^{2}$. The values range from 0.95 for RNZ to 0.97 for MNZ. Moreover, the predicted values of $q_{e}$ are significantly different from the actual experimental values. This suggests that nitroimidazole adsorption onto SiC NPs cannot be described by the pseudo-first order kinetic model. Parameters of other kinetic models are also listed in Table 3. It is obvious that the pseudo-seconder order kinetic model is capable of accurately describing the experimental data of nitroimidazole adsorption. In this case, the model parameters, i.e., $k_{2}$ and $q_{e}$, were obtained from the slope and intercepts of plots of $\left(t / q_{t}\right)$ versus $t$, as shown in Figure 6 . The correlation coefficients $\left(R^{2}\right)$ of linear plots have high values, which suggest that nitroimidazole adsorption onto SiC NPs follows the pseudo-second order kinetic model. It can be seen in Table 3 that there is an excellent agreement between the computed and experimental values of $q_{e}$. Since $d q_{t} / d t$ is proportional to the second power of $\left(q_{e}-q_{t}\right)$, the antibiotic removal will be much faster, initially owing to the higher driving force as compared to the later stages of contact as $q_{t} \rightarrow q_{e}$. Moreover, the rate-limiting step is the surface adsorption, which involves the chemisorption of the antibiotics present in the aqueous solution to the adsorbent surface, due to a physiochemical interaction. 
Table 3. Kinetic parameters for nitroimidazole adsorption onto SiC NPs.

\begin{tabular}{|c|c|c|c|c|}
\hline Kinetic Models & MNZ & DMZ & RNZ & TNZ \\
\hline$q_{\text {experimental }}(\mathrm{mg} / \mathrm{g})$ & $27.04 \pm 0.049$ & $26.10 \pm 0.100$ & $25.02 \pm 0.072$ & $24.00 \pm 0.042$ \\
\hline \multicolumn{5}{|l|}{ Pseudo-first-order } \\
\hline$q_{e}(\mathrm{mg} / \mathrm{g})$ & 23.19 & 21.97 & 21.74 & 21.72 \\
\hline$k_{1}(1 / \min )$ & 0.1651 & 0.1457 & 0.14650 & 0.1324 \\
\hline$R^{2}$ & 0.9723 & 0.9537 & 0.9579 & 0.9720 \\
\hline \multicolumn{5}{|l|}{ Pseudo-second-order } \\
\hline$q_{e}(\mathrm{mg} / \mathrm{g})$ & 31.38 & 30.72 & 30.07 & 30.17 \\
\hline$k_{2}(\mathrm{~g} /(\mathrm{mg} \min ))$ & 0.0089 & 0.0079 & 0.0072 & 0.0055 \\
\hline$R^{2}$ & 0.9954 & 0.9862 & 0.9827 & 0.9784 \\
\hline \multicolumn{5}{|l|}{$\begin{array}{c}\text { Intraparticle } \\
\text { diffusion }\end{array}$} \\
\hline$K_{i}\left(\mathrm{mg} / \mathrm{g} \cdot \min ^{0.5}\right)$ & 3.5283 & 3.1826 & 3.2955 & 3.7271 \\
\hline C & 11.273 & 10.934 & 9.469 & 6.298 \\
\hline$R^{2}$ & 0.9989 & 0.9773 & 0.9583 & 0.9783 \\
\hline
\end{tabular}

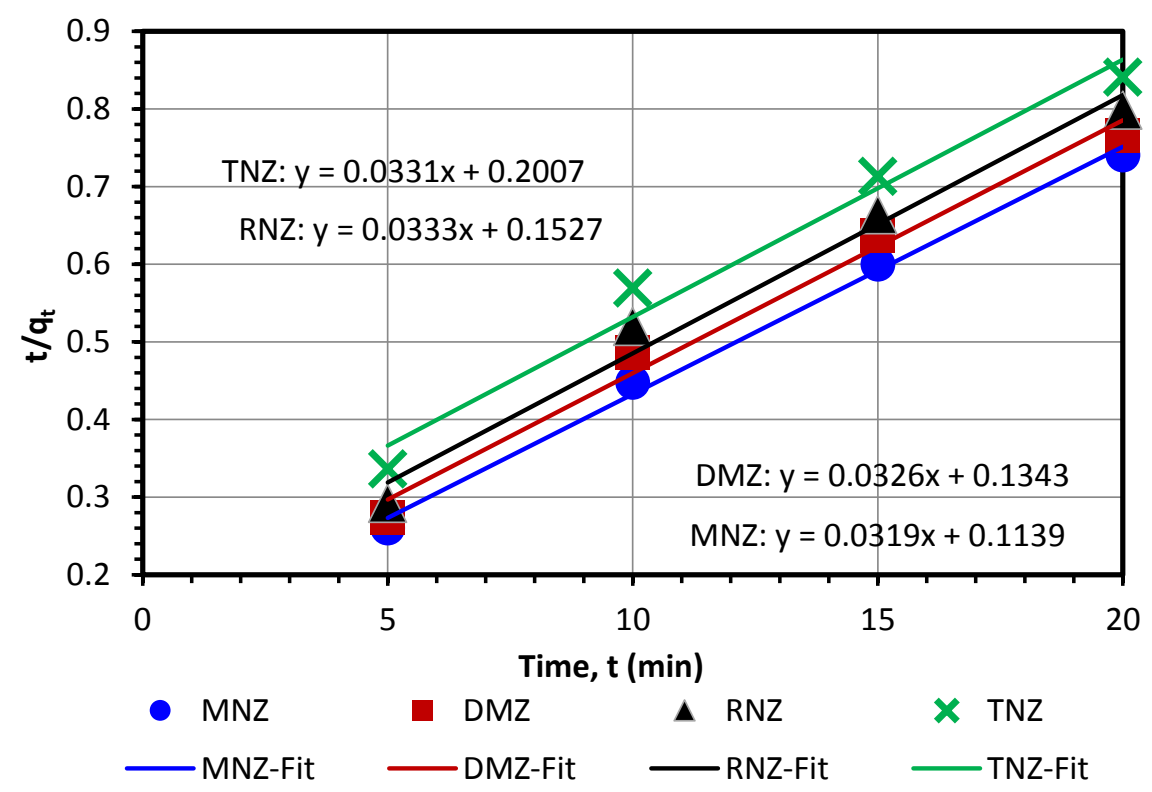

Figure 6. Pseudo-second order kinetic model for nitroimidazole adsorption onto $\operatorname{SiC~NPs~}\left(C_{0}=30 \mathrm{mg} / \mathrm{L}\right.$, $T=25^{\circ} \mathrm{C}$; adsorbent dose $=0.1 \mathrm{~g}, \mathrm{pH}=8$ ).

For the intraparticle diffusion model represented by Equation (4), the nitroimidazole antibiotic uptake at any instance of time depends upon on the intraparticle diffusion coefficient $\left(K_{i}\right)$ and parameter $C$, which is a measure of the thickness of the boundary layer. According to the model, the plot of uptake quantity versus $\sqrt{ } t$ would be linear if intraparticle diffusion governs the process of adsorption. Moreover, if the lines pass through the origin, then the intraparticle diffusion is the rate-controlling step. Plots that do not pass through the origin indicate some degree of boundary layer control. This indicates that other models may control the rate adsorption.

\subsection{Comparison}

In the literature, the comparison of adsorbents is mainly based on the contaminant uptake capacity, which is mostly reported on the basis of per unit mass. Uptakes as high as 500 to $600 \mathrm{mg} / \mathrm{g}$ have been reported when using activated carbon cloth [12], while employing a relatively high initial concentration of the antibiotics. However, Flores-Cano et al. [13] recently used the adsorbent surface 
area as a basis for evaluating the adsorbent performance. The reported uptake in their case reached $567 \times 10^{-3} \mathrm{mg} / \mathrm{m}^{2}$, which was higher than the other adsorbents previously reported in the literature. In the present case, the adsorption capacity varied from 115 to $127 \mathrm{mg} / \mathrm{g}$, which in terms of the surface area, is $2907 \times 10^{-3}$ to $3211 \times 10^{-3} \mathrm{mg} / \mathrm{m}^{2}$. Thus, the values obtained in the present investigation are several times higher than the highest reported so far [13]. Moreover, as pointed out earlier, adsorbents with faster contaminant removal rates are of paramount importance for an efficient and cost-effective implementation of the adsorption-based separation process. Since previous research has focused on improving the adsorption capacity, most adsorbents developed so far generally show a slow uptake of the nitroimidazoles. For example, activated carbon samples using Siris seed pods with second order adsorption kinetics, took almost $180 \mathrm{~min}$ to reach equilibrium [10,11]. On the other hand, the adsorption kinetics of activated carbon cloth with one of the highest adsorption capacities per unit mass, was even slower; taking as long as $220 \mathrm{~min}$ to reach equilibrium. The adsorbents prepared by Flores-Cano et al. [13], with an equilibrium time of $50 \mathrm{~min}$, appear to be faster than most other previously reported adsorbents. However, in the present case, the adsorption kinetics were even faster. The rate constants were $0.0089,0.0079,0.0072$, and 0.0055 g/(mg min), for MNZ, DMZ, RNZ, and TNZ, respectively. These values are several times higher than those reported by Ahmed and Theydan [10,11]. Therefore, the time to reach equilibrium in the present case of the SiC adsorbent was only $20 \mathrm{~min}$, which appears to be shorter than most other adsorbents with a similar adsorption capacity reported in the literature. Since the adsorption is a surface-based rate process, which depends upon the availability of vacant sites on the surface, an adsorbent with a large surface area usually yields a high removal capacity. On the other hand, as far as the removal kinetics are concerned, easy access to the available vacant sites is of paramount importance, owing to the presence of the mass transport resistances, which hinder the movement of adsorbate molecules. Of particular concern is the internal mass transport resistance occurring inside the pores of the adsorbent. In the present case, the vacant sites of SiC NPs are mostly contributed by the external surface, which provides relatively easier access to antibiotic molecules, unlike activated carbon-based adsorbents, where adsorbate molecules have to diffuse through the interstices of the porous structure to find vacant sites for adsorption. As a result, $\mathrm{SiC}$ NPs yield a significantly higher rate of antibiotic removal.

\section{Conclusions}

Rigorous kinetic and equilibrium studies were carried out for the adsorption of nitroimidazole from aqueous solutions onto the SiC NPs synthesized in the present study. Results of adsorption showed that $\mathrm{SiC}$ NPs can be effectively used as adsorbents for the efficient removal of nitroimidazole antibiotics. Isotherm studies indicate that the Langmuir model fitted the experimental data better than the Freundlich and Florry-Huggins isotherm models. On the other hand, the adsorption kinetics were best described by the pseudo-second order kinetic model.

Acknowledgments: The authors acknowledge the Iranian Research Organization for Science and Technology (IROST) for the performance support. KSU authors would like to extend their sincere appreciation to the Deanship of Scientific Research at the King Saud University for its support to Research Group, RGP-1437-003.

Author Contributions: Ali Fakhri conceived, designed and supervised the experiments and put together the initial draft of the paper; Sahar Rashidi performed the experiments; Ahmed A. Ibrahim carried out the literature review; Mohammad Asif analyzed the data, finalized the paper and was the main corresponding author during the review process.

Conflicts of Interest: The authors declare no conflict of interest.

\section{References}

1. Chang, X.; Meyer, M.T.; Liu, X.; Zhao, Q.; Chen, H.; Chen, J.-A.; Qiu, Z.; Yang, L.; Cao, J.; Shu, W. Determination of antibiotics in sewage from hospitals, nursery and slaughter house, wastewater treatment plant and source water in Chongqing region of three gorge reservoir in China. Environ. Pollut. 2010, 158, 1444-1450. [CrossRef] [PubMed] 
2. Halling-Sørensen, B.; Nors Nielsen, S.; Lanzky, P.F.; Ingerslev, F.; Holten Lützhøft, H.C.; Jørgensen, S.E. Occurrence, fate and effects of pharmaceutical substances in the environment-A review. Chemosphere 1998, 36, 357-393. [CrossRef]

3. Aksu, Z.; Tunç, Ö. Application of biosorption for penicillin G removal: Comparison with activated carbon. Process Biochem. 2005, 40, 831-847. [CrossRef]

4. Alcock, R.E.; Sweetman, A.; Jones, K.C. Assessment of organic contanhnant fate in waste water treatment plants I: Selected compounds and physicochemical properties. Chemosphere 1999, 38, 2247-2262. [CrossRef]

5. Lau, A.H.; Lam, N.P.; Piscitelli, S.C.; Wilkes, L.; Danziger, L.H. Clinical pharmacokinetics of metronidazole and other nitroimidazole anti-infectives. Clin. Pharmacokinet. 1992, 23, 328-364. [CrossRef] [PubMed]

6. Tally, F.P.; Sullivan, C.E. Metronidazole: In vitro activity, pharmacology and efficacy in anaerobic bacterial infections. Pharmacother. J. Hum. Pharmacol. Drug Ther. 1981, 1, 28-38. [CrossRef]

7. Cohen, S.H.; Gerding, D.N.; Johnson, S.; Kelly, C.P.; Loo, V.G.; McDonald, L.C.; Pepin, J.; Wilcox, M.H. Clinical practice guidelines for clostridium difficile infection in adults: 2010 update by the society for healthcare epidemiology of America (SHEA) and the infectious diseases society of america (IDSA). Infect. Control Hosp. Epidemiol. 2010, 31, 431-455. [CrossRef] [PubMed]

8. Olson, L.; Rodabaugh, D. Ronidazole in low concentrations in drinking water for treatment and development of immunity to swine dysentery. Am. J. Vet. Res. 1976, 37, 763-767. [PubMed]

9. Gunn-Moore, D.; Lalor, S. Treatment of diarrhoea in cats caused by Tritrichomonas foetus. Vet. Rec. 2011, 168, 56-57. [CrossRef] [PubMed]

10. Ahmed, M.J.; Theydan, S.K. Microwave assisted preparation of microporous activated carbon from siris seed pods for adsorption of metronidazole antibiotic. Chem. Eng. J. 2013, 214, 310-318. [CrossRef]

11. Ahmed, M.J.; Theydan, S.K. Microporous activated carbon from siris seed pods by microwave-induced koh activation for metronidazole adsorption. J. Anal. Appl. Pyrolysis 2013, 99, 101-109. [CrossRef]

12. Ocampo-Pérez, R.; Orellana-Garcia, F.; Sánchez-Polo, M.; Rivera-Utrilla, J.; Velo-Gala, I.; López-Ramón, M.V.; Alvarez-Merino, M.A. Nitroimidazoles adsorption on activated carbon cloth from aqueous solution. J. Colloid Interface Sci. 2013, 401, 116-124. [CrossRef] [PubMed]

13. Flores-Cano, J.V.; Sánchez-Polo, M.; Messoud, J.; Velo-Gala, I.; Ocampo-Pérez, R.; Rivera-Utrilla, J. Overall adsorption rate of metronidazole, dimetridazole and diatrizoate on activated carbons prepared from coffee residues and almond shells. J. Environ. Manag. 2016, 169, 116-125. [CrossRef] [PubMed]

14. Ding, H.; Bian, G. Adsorption of metronidazole in aqueous solution by fe-modified sepiolite. Desalin. Water Treat. 2015, 55, 1620-1628. [CrossRef]

15. Rivera-Utrilla, J.; Prados-Joya, G.; Sánchez-Polo, M.; Ferro-García, M.A.; Bautista-Toledo, I. Removal of nitroimidazole antibiotics from aqueous solution by adsorption/bioadsorption on activated carbon. J. Hazard. Mater. 2009, 170, 298-305. [CrossRef] [PubMed]

16. Sánchez-Polo, M.; López-Peñalver, J.; Prados-Joya, G.; Ferro-García, M.A.; Rivera-Utrilla, J. Gamma irradiation of pharmaceutical compounds, nitroimidazoles, as a new alternative for water treatment. Water Res. 2009, 43, 4028-4036. [CrossRef] [PubMed]

17. Johnson, M.B.; Mehrvar, M. Aqueous metronidazole degradation by $\mathrm{UV} / \mathrm{H}_{2} \mathrm{O}_{2}$ process in single-and multi-lamp tubular photoreactors: Kinetics and reactor design. Ind. Eng. Chem. Res. 2008, 47, 6525-6537. [CrossRef]

18. Sánchez-Polo, M.; Rivera-Utrilla, J.; Prados-Joya, G.; Ferro-García, M.A.; Bautista-Toledo, I. Removal of pharmaceutical compounds, nitroimidazoles, from waters by using the ozone/carbon system. Water Res. 2008, 42, 4163-4171. [CrossRef] [PubMed]

19. Shemer, H.; Kunukcu, Y.K.; Linden, K.G. Degradation of the pharmaceutical metronidazole via UV, fenton and photo-fenton processes. Chemosphere 2006, 63, 269-276. [CrossRef] [PubMed]

20. Ingerslev, F.; Halling-Sørensen, B. Biodegradability of metronidazole, olaquindox, and tylosin and formation of tylosin degradation products in aerobic soil-manure slurries. Ecotoxicol. Environ. Saf. 2001, 48, 311-320. [CrossRef] [PubMed]

21. Habib, M.J.; Asker, A.F. Complex formation between metronidazole and sodium urate: Effect on photodegradation of metronidazole. Pharm. Res. 1989, 6, 58-61. [CrossRef] [PubMed]

22. Méndez-Díaz, J.D.; Prados-Joya, G.; Rivera-Utrilla, J.; Leyva-Ramos, R.; Sánchez-Polo, M.; Ferro-García, M.A.; Medellín-Castillo, N.A. Kinetic study of the adsorption of nitroimidazole antibiotics on activated carbons in aqueous phase. J. Colloid Interface Sci. 2010, 345, 481-490. [CrossRef] [PubMed] 
23. Shi, L.; Zhao, H.; Yan, Y.; Li, Z.; Tang, C. Synthesis and characterization of submicron silicon carbide powders with silicon and phenolic resin. Powder Technol. 2006, 169, 71-76. [CrossRef]

24. Raman, V.; Bahl, O.P.; Dhawan, U. Synthesis of silicon carbide through the sol-gel process from different precursors. J. Mater. Sci. 1995, 30, 2686-2693. [CrossRef]

25. Larpkiattaworn, S.; Ngernchuklin, P.; Khongwong, W.; Pankurddee, N.; Wada, S. The influence of reaction parameters on the free si and c contents in the synthesis of nano-sized sic. Ceram. Int. 2006, 32, 899-904. [CrossRef]

26. Lin, Y.-J.; Chuang, C.-M. The effects of transition metals on carbothermal synthesis of $\beta$-sic powder. Ceram. Int. 2007, 33, 779-784. [CrossRef]

27. Kurtenbach, D.; Mitchell, B.S.; Zhang, H.; Ade, M.; Müller, E. Crystallization kinetics of amorphous silicon carbide derived from polymeric precursors. Thermochim. Acta 1999, 337, 155-161. [CrossRef]

28. Koc, R.; Glatzmaier, G.; Sibold, J. B-sic production by reacting silica gel with hydrocarbon gas. J. Mater. Sci. 2001, 36, 995-999. [CrossRef]

29. Sharma, R.; Rao, D.V.S.; Vankar, V.D. Growth of nanocrystalline $\beta$-silicon carbide and nanocrystalline silicon oxide nanoparticles by sol gel technique. Mater. Lett. 2008, 62, 3174-3177. [CrossRef]

30. Fakhri, A.; Adami, S. Adsorption and thermodynamic study of cephalosporins antibiotics from aqueous solution onto mgo nanoparticles. J. Taiwan Inst. Chem. Eng. 2014, 45, 1001-1006. [CrossRef]

31. Fakhri, A. Assessment of ethidium bromide and ethidium monoazide bromide removal from aqueous matrices by adsorption on cupric oxide nanoparticles. Ecotoxicol. Environ. Saf. 2014, 104, 386-392. [CrossRef] [PubMed]

32. Fakhri, A. Utilization of tungsten trioxide nanoparticles and nickel oxide pillared montmorillonite nanocomposites for the adsorption of the drug dexamethasone from aqueous solutions. RSC Adv. 2015, 5, 22199-22208. [CrossRef]

33. Langmuir, I. The adsorption of gases on plane surfacesof glass, mica and platinum. J. Am. Chem. Soc. 1918, 40, 1361-1403. [CrossRef]

34. Freundlich, H. Uber die adsorption in 1 osungen (adsorption in solution). Z. Phys. Chem. 1906, 57, $384-470$.

35. Jnr, M.H.; Spiff, A.I. Equilibrium sorption study of $\mathrm{Al}^{3+}, \mathrm{Co}^{2+}$ and $\mathrm{Ag}^{+}$in aqueous solutions by fluted pumpkin (telfairia occidentalis HOOK f) waste biomass. Acta Chim. Slov. 2005, 52, 174-181.

36. Rajamohan, N. Equilibrium studies on sorption of an anionic dye onto acid activated water hyacinth roots. Afr. J. Environ. Sci. Technol. 2009, 3, 399-404.

37. Özdemir, Y.; Doğan, M.; Alkan, M. Adsorption of cationic dyes from aqueous solutions by sepiolite. Microporous Mesoporous Mater. 2006, 96, 419-427. [CrossRef]

(C) 2017 by the authors; licensee MDPI, Basel, Switzerland. This article is an open access article distributed under the terms and conditions of the Creative Commons Attribution (CC BY) license (http:/ / creativecommons.org/licenses/by/4.0/). 